\title{
Apoptosis in natural rabies virus infection in dogs
}

\author{
Sevil Atalay Vural ${ }^{1}$, Mehmet Fatih Bozkurt ${ }^{2}$, Ali Ozkara ${ }^{3}$, \\ Mehmet Eray Alcigir ${ }^{1}$, Fatma Sayin Ilhan ${ }^{4}$ \\ ${ }^{1}$ Department of Pathology, Faculty of Veterinary Medicine, \\ Ankara University, Diskapi, 06110, Ankara, Turkey \\ ${ }^{2}$ Department of Pathology, Faculty of Veterinary Medicine, \\ Afyon Kocatepe University, 03200, Afyonkarahisar, Turkey \\ ${ }^{3}$ Pendik Veterinary Control and Research Institute, Pendik, 34890, Istanbul, Turkey \\ ${ }^{4}$ Department of Pathology, Faculty of Veterinary Medicine, \\ Balıkesir University, 10145, Balıkesir, Turkey \\ sevilvural@yahoo.com
}

Received: October 30, 2015 Accepted: August 29, 2016

\begin{abstract}
Introduction: In the present study apoptosis was investigated in the cornu ammonis and cerebellum of 10 dogs naturally infected with rabies virus. Diagnosis of rabies was based on the results of fluorescent antibody staining and experimental inoculation. Material and Methods: The paraffin tissue sections were stained with haematoxylin and eosin, avidin-biotin complex peroxidase (ABC-P), and terminal deoxynucleotidyl transferase biotin-dUTP nick end-labelling (TUNEL) methods. Results: Histopathological examination revealed encephalomyelitis of varying severity and the presence of Negri bodies. Dense rabies antigens were determined in the motor neurons with ABC-P method. On the other hand, Bcl-2 protein and Bax protein gave positive reaction in seven and five cases, respectively. TUNEL staining demonstrated very marked apoptotic changes in the nuclei of neurons localised deep in the substantia alba of the cerebellum. Similar changes were also determined in perivascular mononuclear cells and glia cells within the substantia alba. No apoptopic changes were found in the motor neurons of the cornu ammonis. Conclusion: The absence of apoptotic changes in the neurons was considered to be the consequence of the necrotic changes that developed in these neurons.
\end{abstract}

Keywords: dogs, rabies, central nervous system, apoptosis, histopathology.

\section{Introduction}

Rabies is caused by rabies virus (RABV) belonging to the genus Lyssavirus of Rhabdoviridae family, which affects all warm-blooded animals as well as humans $(15,24)$. Globally, around 3.9 billion people are at risk of contracting rabies and more than 150 countries are affected, with billions of dollars being spent on protection $(3,15,17)$. RABV has two biotypes known as "street virus" and "fixed virus". Fixed RABV, vaccine strains, are laboratory biotypes and is not secreted in saliva. Street RABV is tropic for salivary glands (18). Animals and humans acquire the infection by introduction of RABV-laden saliva through a bite of a rabid animal, or mucosal exposure. On gaining receptor-mediated entry into the neuron, the virus replicates and disseminates in the central nervous system by fast axonal transport along neuroanatomical connections $(8,18)$. Specific macroscopical lesions are not present, but self-inflicted wounds and foreign bodies in the stomach of a carnivore should raise suspicion. Microscopically, pathognomonic findings are characterised by non-suppurative encephalomyelitis, ganglioneuritis, and parotid adenitis $(18,21)$. For this reason the research projects aim to find the fastest and safest methods of early diagnosis $(25,26)$.

RABV is a neurotrophic virus which kills or causes function disorders by infecting the neurons at the central nervous system. There is a common opinion that cell death occurs via apoptosis $(5,23)$. Apoptosis was firstly defined in 1972 as death of cells caused by demolition of the genes that control the internal 
mechanism of cells and results in the fractures of the DNA helix. It starts with the stimulation of some internal and external factors. There are biochemical and morphological changes in the stimulated cells (6). These reactions are formed directly or indirectly by an increase in the level of substances that are under control of apoptotic genes (Bax, Bad, Bad proteinproapoptotic) or anti-apoptotic genes (Bcl-2, Bcl-xl, Boa). All these substances and energy required for apoptosis are supported by mitochondria $(7,20)$.

In these days, the role of apoptosis has been studied in regard to experimental infections of mice with Sindbis virus, Crosse virus, and reovirus (4, 10, $14,16)$. The present study describes the distribution of viral antigen and apoptosis in the central nervous system of dogs infected with street rabies virus.

\section{Material and Methods}

Animals. The study involved $10 \mathrm{dogs}$ which had been determined to be rabies-positive based on the results of fluorescent antibody staining and experimental inoculation.

Sample collection and histopathological examinations. The cerebellum and cornu ammonis were fixed in $10 \%$ buffered formalin, processed by routine method, and embedded in paraffin. The $5 \mu \mathrm{m}$ sections were mounted on glass slides, and stained with haematoxylin and eosin (HE). Selected sections were also stained with cresyl violet.

Immunoperoxidase staining. The sections were stained for rabies virus antigen by avidin-biotin complex peroxidase (ABC-P) method using polyclonal rabbit anti-rabies virus nucleoprotein sera (1:500, Animal Disease Research Institute, Canada) and polyclonal rabbit anti-Bax and Bcl-2 antibodies (1:500, Santa Cruz Biotechnology, USA) according to the procedure provided by the producer (LSAB Kit, Dako). The colour was developed by a final incubation with 3-amino-9 ethylcarbazole (AEC). As a control group, the samples were treated with normal rabbit sera instead of primary antibody.

In-situ detection of apoptotic cells by TUNEL assay. DNA fragmentation was assessed in situ in sections using the terminal deoxynucleotidyl transferase (TdT)-mediated dUTP-digoxigenin nick end-labelling (TUNEL) kit as recommended by the manufacturer (In Situ Cell Death Detection Kit, POD, Roche, Germany). To visualise the reaction products, the samples were incubated with AEC and counterstained with Gill's haematoxylin. As control, the samples were treated with labelling solution instead of TdT.

The severity of immunoreactivity was graded according to the density in 10 different microscopic areas as + mild, ++ moderate, +++ severe, - no staining.

\section{Results}

Histopathologically, many of the vessels in the cornu ammonis and cerebellum were hyperaemic and surrounded by mononuclear cells. Similar perivascular cells were also seen around meningeal vessels. Some neurons were degenerative or necrotic. Neuronophagia and Babes' nodules were visible. The proliferation of glia cells was focally observed and different numbers of Negri bodies were seen in all samples (Figs 1-3). Morphological changes related to apoptosis also drew attention, especially in internal/external granular layer (Fig. 4) and at cerebellar nucleus in the cerebellum, to a lesser extent in the neurons located in the cornu ammonis. The most evident feature of these changes was the phenomenon of neurons becoming smaller and shrinking, cytoplasm getting narrow, and chromatins coming together as rough particles near the nuclear membrane.

Immunohistochemically, high levels of rabies virus antigen were detected in motor neurons of the cornu ammonis, Purkinje cells, external layer, and cerebellar nucleus (Fig. 5) in all animals. Staining of Bcl-2 protein was positive in seven dogs and Bax protein in five animals (Figs 6-9). Bax protein was detected in the Purkinje cells, cerebellar nucleus, and external granular layer of the cerebellum contrary to the cornu ammonis. On the other hand, Bcl-2 protein was localised in the Purkinje cells, cerebellar nucleus, and motor neurons of the cornu ammonis.

At TUNEL staining, the most evident reaction was found in external/internal granular layer and cerebellar nucleus of the cerebellum. Similar changes were seen in perivascular mononuclear cells (Fig. 10) and glia cells which were located in substantia alba. At the same time, the differences in localisation and degree of positive reaction were not significant in the cerebellum of all dogs. No positive TUNEL reactions were seen in the cornu ammonis.

The results are summarised in Tables 1 and 2 .

Table 1. Changes in cerebellum cells affected with rabies virus

\begin{tabular}{|c|c|c|c|c|c|}
\hline \multirow[t]{3}{*}{ Affected group of cells } & \multicolumn{5}{|c|}{ Pathomorphological and immunohistochemical findings } \\
\hline & \multirow{2}{*}{$\begin{array}{l}\text { Morphological } \\
\text { changes }\end{array}$} & \multirow{2}{*}{$\begin{array}{l}\text { TUNEL } \\
\text { positivity }\end{array}$} & \multicolumn{3}{|c|}{ Immunohistochemical examinations } \\
\hline & & & Viral antigen & Bcl-2 protein & Bax protein \\
\hline Purkinje cells & + & - & $+/+++$ & + & + \\
\hline External granular layer & + & + & $++/+++$ & - & + \\
\hline Internal granular layer & + & + & + & - & + \\
\hline Cerebellar nucleus & + & + & $++/+++$ & + & + \\
\hline
\end{tabular}




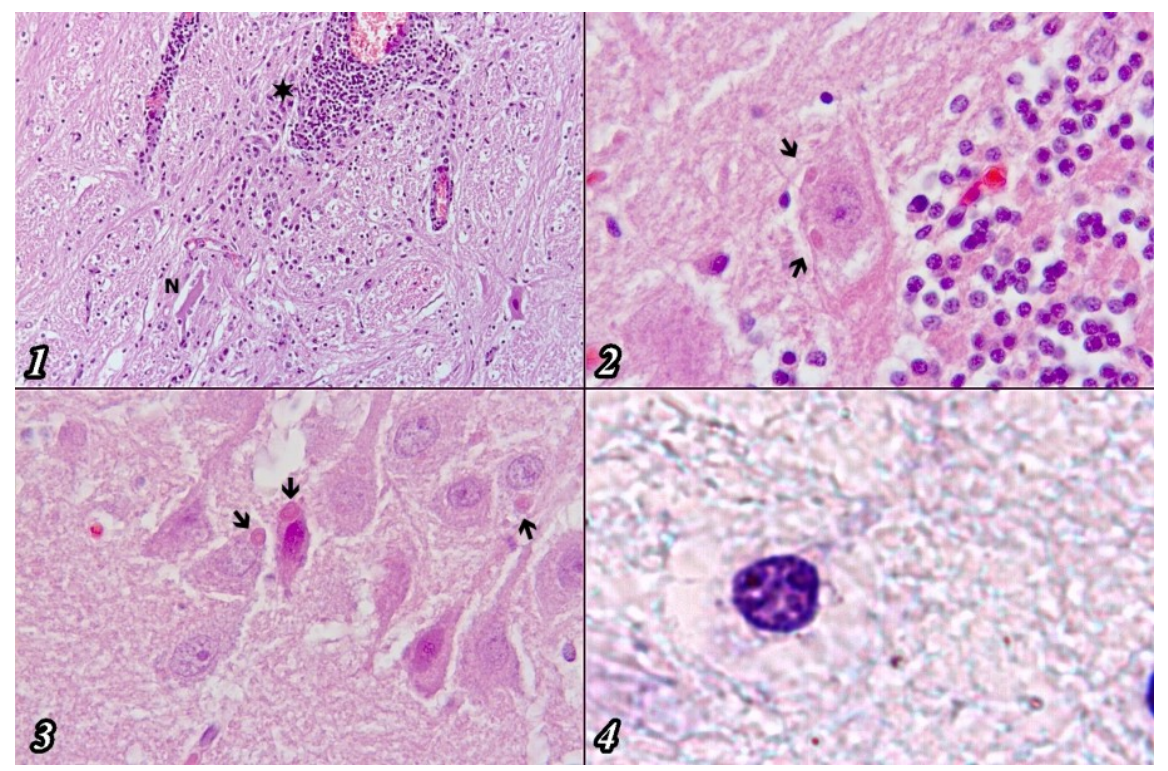

Fig. 1. Neuronophagia $(\mathrm{N})$ and perivascular mononuclear cell infiltration (star), cerebellum, HE, 100× Fig. 2. Negri bodies in Purkinje cells (arrows), dog, HE, 400×

Fig. 3. Negri bodies in motor neuron (arrows), cornu ammonis, dog, HE, 400×

Fig. 4 Apoptotic changes and dense chromatins in nucleus, dog, Cresyl violet, 1250×

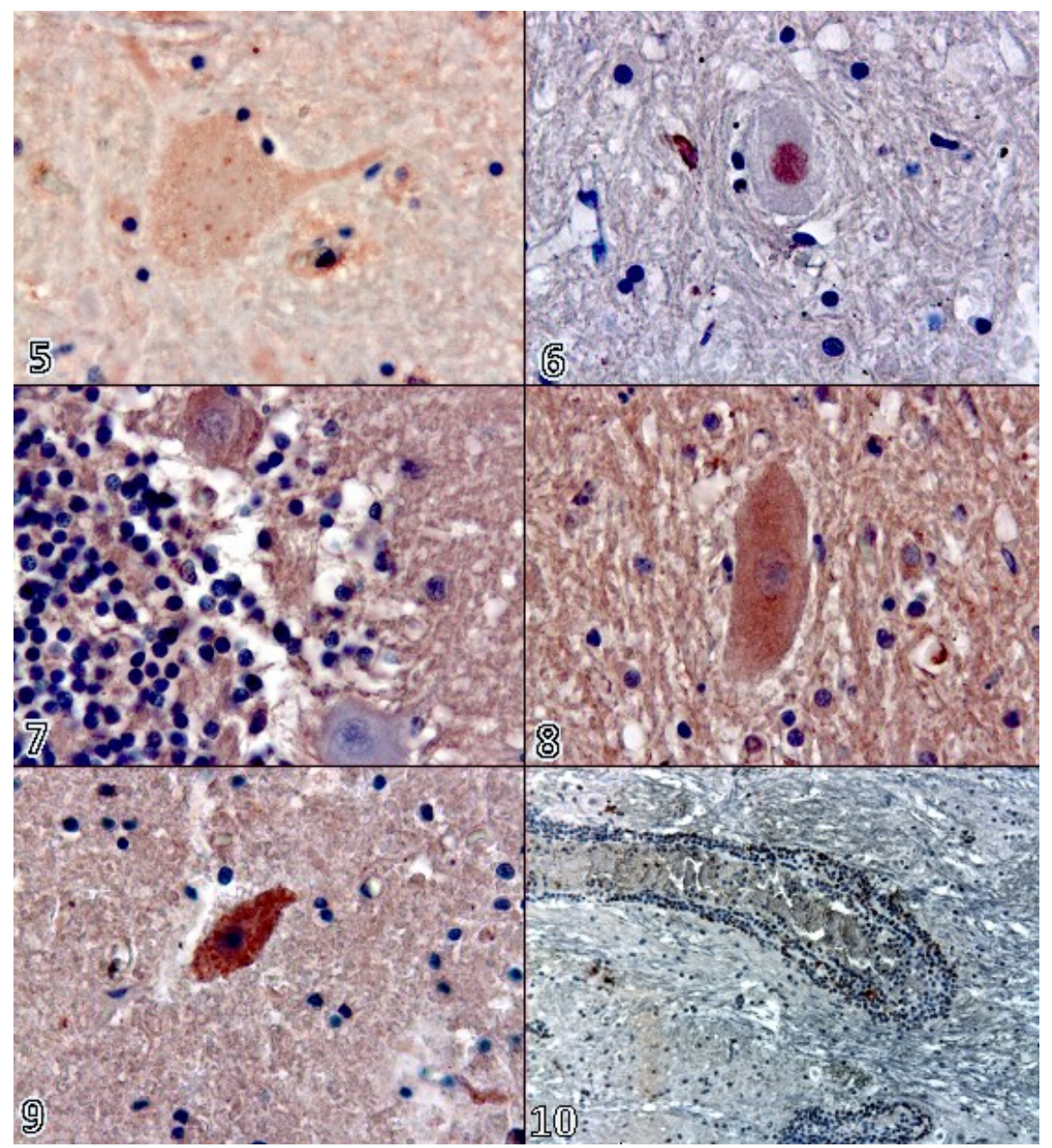

Fig. 5. Viral antigen at cerebellar nucleus, dog, ABC-P, 400×

Fig. 6. Bcl-2 protein in cerebellar nucleus, dog, $\mathrm{ABC}-\mathrm{P}, 400 \times$

Fig. 7. Bcl-2 protein in Purkinje cells, dog, ABC-P, $400 \times$

Fig. 8. Bax protein in cerebellar nucleus, dog, ABC-P, 400×

Fig. 9. Apoptosis of cerebellar nucleus, dog, TUNEL, 400×

Fig. 10. Apoptosis of perivascular mononuclear cells, dog, TUNEL, 100× 
Table 2. Changes in cornu ammonis cells affected with rabies virus

\begin{tabular}{llllll}
\hline \multirow{2}{*}{ Affected group of cells } & \multicolumn{3}{c}{ Pathomorphological and immunohistochemical findings } \\
\hline & $\begin{array}{l}\text { Morphological } \\
\text { changes }\end{array}$ & $\begin{array}{l}\text { TUNEL } \\
\text { positivity }\end{array}$ & \multicolumn{3}{c}{ Immunohistochemical examinations } \\
\cline { 3 - 6 } & + & - & Viral antigen & Bcl-2 protein & Bax protein \\
\hline CA-C1 & - & - & $++/+++$ & + & - \\
\hline CA-C2 & - & - & $++/+++$ & + & - \\
\hline CA-C3 & + & - & $++/+++$ & - & - \\
\hline Dentate gyrus & + & $++/+++$ & - & - \\
\hline
\end{tabular}

\section{Discussion}

Apoptosis, defined as the programmed cell death, is a widespread cell biological process. Apoptosis occurs normally during development and aging and as a homeostatic mechanism maintaining cell populations in tissues. It also occurs as a defence mechanism, e.g. in immune reactions or when cells are damaged by disease or toxic agents $(7,14,19)$.

Apoptosis is tightly regulated and can be induced by a variety of stimuli and conditions, both physiological and pathological, such as viruses and other factors causing disruption of cellular functions (7). Apoptosis classically occurs via either the intrinsic or extrinsic pathways. In brief, the intrinsic pathway occurs in the mitochondrion when apoptosis is triggered by a variety of intracellular signals, where cytochrome $\mathrm{c}$ is released from the mitochondrial membrane to the cytoplasm and then activates caspase9 which subsequently activates caspase-3 and DNA cleavage $(2,14,22)$. By contrast, the extrinsic pathway can be induced by members of the tumour necrosis factor (TNF) family of cytokine receptors, such as TNFR1 and Fas Ligand (FasL). They recruit adapter proteins to their cytosolic death domains (DDs), which bind procaspases containing deatheffector domains (DED), particularly procaspase-8 $(2,14)$.

Apoptosis has typical morphological and biochemical characteristics. The morphological changes of infected cells are evidenced by smaller nucleus, denser chromatin, fragmentation of nuclei, and separation of DNA from internucleosomal space. Genomic DNA internucleosomal fragmentation is the most significant biochemical sign of apoptosis. The energy consumed by apoptotic processes leads cell to death. Caspase family proteases, Bcl-2 family proteins, and p53 gene product play a central role in the process of apoptotic cell death. The Bcl-2 family of proteins governs mitochondrial membrane permeability and can be either pro-apoptotic or anti-apoptotic $(1,13)$.

In the recent years, neurotropic viruses in particular have been shown to induce apoptosis within the CNS, and depletion of these non-regenerating neuronal cells by apoptosis may result in neurological morbidity $(1,5,7,10,12,14,27)$. This association between viral infection of the CNS and apoptosis has spawned a new area of rabies virus research. For this purpose, the effect of laboratory adapted rabies virus strains is researched experimentally, and morphological changes related to apoptosis and TUNEL positive reactions are investigated (9). These reactions are mostly observed in the neurons $(10,12)$. TUNEL positive neurons were seen in all layers of the cerebral cortex, cingulate gyrus, Ammon's horn in the hippocampus, and neurons in the thalamic and hypothalamic regions after infection with CVS strain of rabies virus. In addition to neurons, the inflammatory cells lining the meninges, ependymal cells lining the ventricle, cells of the choroids plexus, and rare glial and microglial cells in the cortex and white matter also showed labelling (21). In spite of the presence of viral antigen, TUNEL reaction does not occur in the Purkinje cells of the cerebellum (12). Immunohistochemically, rabies virus antigen was marked, together with morphological changes, both in the motor neurons of the cornu ammonis, Purkinje cells, and cerebellar nucleus. However, TUNEL positive reactions were not seen in the cornu ammonis contrary to the cerebellum. This situation may be interpreted as necrosis of neurons or may suggest that these neurons are more resistant to apoptosis than other neuronal cell types, although it seems less probable. Similar changes were observed in perivascular mononuclear cells and glia cells which were located in the substantia alba. Yan et al (27) inoculated wild type virus into experimental mice, and reported very few TUNEL positive neurons despite the presence of clinical signs of the disease, suggesting that apoptosis may not be an essential neuropathogenic mechanism. Street-virusinfected suckling mice revealed TUNEL labelling of occasional microglial cells in the cerebral cortex and brain stem (21). On the other hand, evaluation of morphological features of neuronal apoptosis in postmortem brain tissue from human rabies victims collected from different countries suggested that neuronal apoptosis does not play an important role in human rabies encephalitis (11).

Jackson and Park (10) found Bax protein associated with apoptosis in the cerebral cortex and pyramidal neurons of the cornu ammonis, indicating that Bcl-2 family proteins play an important role in experimental rabies. In the present study, Bax-positive staining was observed especially in cerebellar nucleus and external granular layers of cerebellum, but no positive reaction was noted in the cornu ammonis. In the same tissues, more significant positive reactions were observed in the case of Bcl-2 protein. These results suggested that there was no apoptotic effect in tissues, and this has been also interpreted as an early 
stage of infection. The staining of both proteins was not detectable due to long incubation and necrosis of cells.

The importance of this study stems from the fact that the previously published reports on neuropathogenesis of rabies employed animal models challenged with laboratory-adapted viral strains in experimentally infected mice and cell cultures. Pathogenetic mechanism mediating the disease was not well characterised. This research evaluated apoptotic changes in natural rabies virus infection of dogs, thus using different animal model as well as different virus type, which increased the value of the results, considering the fact that the number of studies using natural rabies infection is limited.

The presence of TUNEL positive-staining inflammatory cells was evident (21). On the other hand, the varying results of previous research reports and those of this study could be related to differences in virus strain, route of inoculation, permissiveness, and time of infection. Thus, the presented results may broaden the knowledge on the course of street rabies virus infection in dogs.

Conflict of Interests Statement: The authors declare that there is no conflict of interests regarding the publication of this article.

Financial Disclosure Statement: The present work was financially supported by the Scientific Research Project Fund from Ankara University.

Animal Rights Statement: None required.

Acknowledgements: We gratefully thank Dr. Alexander Wandaler (Canada) for hyperimmunsera.

\section{References}

1. Arnoult D., Skaletskaya A., Estaquier J., Dufour C., Goldmacher V.S.: The murine cytomegalovirus cell death suppressor m38.5 binds Bax and blocks Bax-mediated mitochondrial outer membrane permeabilization. Apoptosis 2008, 13, 1100-1110.

2. Aubert M., Pomeranz L.E., Blaho J.A.: Herpes simplex virus blocks apoptosis by precluding mitochondrial cytochrome c release independent of caspase activation in infected human epithelial cells. Apoptosis 2007, 12, 19-35.

3. Benjamin M.D., Glenn F.R., Mathiass J.S.: Everything you always wanted to know about rabies virus (But were afraid to ask). Annu Rev Virol 2015, 2, 451-471.

4. Baloul L., Lafon M.: Apoptosis and rabies virus neuroinvasion. Biochimie 2003, 85, 777-788.

5. Bredesen D.E.: Neural apoptosis. Ann Neur 1995, 38, 839-851.

6. Cooper B.J.: Disease at the cellular level. In: Mechanism of disease, a textbook of comparative general pathology, edited by D.O. Slauson, B.J. Cooper, Mosby, USA, 2002, pp. 16-76.

7. Elmore S.: Apoptosis: A review of programmed cell death. Toxicol Pathol 2007, 35, 495-516.
8. Gomes-Leal W., Marthins L.C., Diniz J.A., Dos Santos Z.A., Borges J.A., Macedo C.A., Medeiros A.C., De Paula L.S., Guimarães J.S., Freire M.A., Vasconcelos P.F., PicançoDiniz C.W.: Neurotropism and neuropathological effects of selected rhabdoviruses on intranasally-infected newborn mice. Acta Tropica 2006, 97, 126-139.

9. Jackson A.C.: Apoptosis in experimental rabies in bax-deficient mice. Acta Neuropathol 1999, 98, 288-294.

10. Jackson A.C., Park H.: Apoptotic cell death in experimental rabies in suckling mice. Acta Neuropathol 1998, 95, 159-164.

11. Jackson A.C., Randle E., Lawrance G., Rossiter J.P.: Neuronal apoptosis does not play an important role in human rabies encephalitis. J Neurovirol 2008, 14, 368-375.

12. Jackson A.C., Rossiter J.P.: Apoptosis plays in important role in experimental rabies virus infection. J Virol 1997, 71, 5603-5607.

13. Jafari A.I., Sankian M., Ahmadpour S., Varasteh A.R., Haghir H.: Evaluation of Bcl-2 family gene expression and Caspase-3 activity in hippocampus STZ-induced diabetic rats. Exp Diabetes Res 2008, 12, Article ID 638467.

14. Kennedy P.G.E.: Viruses, apoptosis, and neuroinflammation a double-edged sword. J Neurovirol 2015, 21, 1-7.

15. Knobel D.L., Cleaveland S., Coleman P.G., Fevre E.M., Meltzer M.I., Miranda M.E., Shaw A., Zinsstag J., Meslin F.X.: Re-evaluating the burden of rabies in Africa and Asia. Bull World Health Org 2005, 83, 360-368.

16. Lewis J., Wesselingh S.L., Griffin D.E., Hardwick J.M.: Alphavirus-induced apoptosis in mouse brains correlates with neurovirulence. J Virol 1996, 70, 1828-1835.

17. Mathers C.D., Ezzati M., Lopez A.D.: Measuring the burden of neglected tropical diseases: The global burden of disease framework. Plos neglected Trop Dis 2007, 1, 1-15.

18. Maxie M.G., Youssef S.: Lyssavirus infections. In: Jubb, Kennedy, and Palmer's Pathology of Domestic Animals/Nervous system, edited by G.M. Maxie, Saunders Elsevier, Edinburgh, 2007, pp. 413-416.

19. Norbury C.J., Hickson I.D.: Cellular responses to DNA damage. Annu Rev Pharmacol Toxicol 2001, 41, 367-401.

20. Pollack M., Leeuwenburgh C.: Mitochondrial control of apoptosis in aging and exercise. http://grove.ufl.edu/ cleeuwen/ mtapoptosis.html., 2009.

21. Suja M.S., Mahadevan A., Madhusudana S.N., Shankar S.K.: Role of apoptosis in rabies viral encephalitis: a comparative study in mice, canine, and human brain with a review of literature. Path Res Intern 2011, Article ID 374286.

22. Sun X.M., MacFarlane M., Zhuang J., Wolf B.B., Green D.R., Cohen G.M.: Distinct caspase cascades are initiated in receptormediated and chemical-induced apoptosis. J Biol Chem 1999, 274: 5053-5060.

23. Thompson C.B.: Apoptosis in the pathogenesis and treatment of disease. Science 1995, 267, 1456-1462.

24. Townsend S.E., Lembo T., Cleaveland S., Meslin F.X., Miranda M.E., Putra A.A., Haydon D.T., Hampson K.: Surveillance guidelines for disease elimination: A case study of canine rabies. Comp Immunol Microbiol Infect Dis 2013, 36, 249-261.

25. Vural Atalay S.: The comparison of histopathological, immunoperoxidase and immunofluorescence techniques in the diagnosis of rabies in dogs. Eurasian J Vet Sci 1999, 15, 35-50.

26. Vural Atalay S., Alcigir G., Berkin S.: Immunohistochemical and histopathological studies of fixed rabies virus in goats. Onderstepoort J Vet Res 2001, 68, 83-89.

27. Yan X., Prosniak M., Curtis M.T., Weiss M.L., Faber M., Dietzschold B., Fu Z.F.: Silver-haired bat rabies virus variant does not induce apoptosis in the brain of experimentally infected mice. J Neurovirol 2001, 7, 518-527. 